\title{
TAXONOMY OF MULTIPLE LEVELS OF SWOT ANALYSIS IN PROJECT MANAGEMENT
}

\author{
Ganesh Vaidyanathan, Indiana University South Bend, gvaidyan@iusb.edu \\ Asghar Sabbaghi, Indiana University South Bend, sabbaghi@iusb.edu
}

\begin{abstract}
SWOT analysis is a method that is usually used in strategic planning to evaluate the strengths, weaknesses, opportunities, and threats in an organization. SWOT analysis involves identifying both the internal and external factors that are favorable and unfavorable to achieve the goals of an organization. A multi-layered SWOT analysis is presented in this paper may be used in different phases or stages of a project. The three layers may be used by project managers and stakeholders either to assess and mitigate project risks or even to terminate a project at some point.
\end{abstract}

Keywords: Project Management, SWOT analysis

\section{INTRODUCTION}

There are many challenging issues in managing projects particularly those involve information technology planning and implementation. Most of these issues stem from uncertainties surrounding the various elements of the project such as supply chain process and availability of appropriate resources, environmental changes and innovations, relevant skills, and technical characteristics of the project. These uncertainties, particularly those related to external environment, have traditionally perceived as the risks that negatively affect the success of the project. Therefore, the management of uncertainties in project management has often been viewed as reducing the uncertainties and the risks associated with the project. In particular, risk is understood to be an event or condition that may occur and would cause a harmful or negative effect that can adversely affect the prospects of achieving a desired goal [1]. Thus risk management relates to decisions about such potentially harmful or negative effects. This understanding is adopted by other studies with a keen awareness of the philosophical and pragmatic implications, and consequently adopted alternative definitions. Williams [11] recommended using risk register to integrate risk management in project definition, Chapman [4] discussed Project Risk Analysis and Management (PRAM) process developed by Association of Project Managers, and Baldry [3] studied risk management applied in managing public sector capital projects. Recently, benefits and applications of implementing risk management principles, tools, and techniques were researched by many scholars $[5,2]$.

Project management essentially has been increasingly effective in managing projects in organizations. Therefore, while project management has to support the competitive strategy of an organization and deliver positive outcomes such as fast-time-to-market products, efficient services or cost-effective systems, it has to manage environmental uncertainties and mitigate the relevant risks as well. Studies have linked project management with strategy while selecting projects [6]. In fact, organizations align their projects to their strategies and research shows that strategic planning activities like internal analysis provide strong links to project management processes and activities [7].

SWOT (Internal Strengths and Weaknesses, and external environmental Opportunities and Threats) analysis is one of the tools used extensively in organizations to identify and to analyze the internal dynamics of various resources as well as the external factors, particularly the uncertainties affecting the success/failure in any project. The technique is credited to Albert Humphrey, who led a convention at Stanford University in the 1960s and 1970s using data from Fortune 500 companies [10]. This involves identification and analysis of the organizational internal strengths and 
weaknesses as well as the external environmental opportunities and threats specific to the project. In this paper, we focus on SWOT analysis as a tool to be used in all possible phases or stages of a project. Although research shows that SWOT analysis is used extensively during project planning and risk analysis activities, there is a need for further research to show how to use this simple tool in the other stages of a project. Project management stages will be described in the next section followed by an in-depth description of SWOT analysis. The paper will conclude with a discussion on further areas of research.

\section{Project Management Stages}

Project management is made up of many stages. Even though projects are implemented to realize different goals using different resources in different parts of the globe by various industries and organizations, projects have a common theme and the same set of stages as shown in Figure 1. Project management stages used to realize project success include:

Defining project goals which include good rationale and alignment to corporate goals;

Organizing projects with a sound organizational structure and associated channels of communication, accountabilities, responsibilities, and reporting facilities;

Defining project scope to reflect customer requirements;

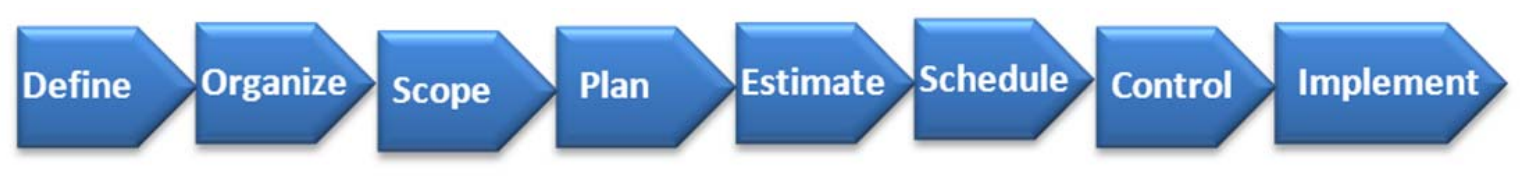

Figure 1. Stages of Project Management

Planning projects to include all activities with milestones;

Estimating project cost and schedule with necessary resources to accomplish the required performance measures and project value;

Scheduling all project activities;

Monitoring and controlling scope, time, cost, resources, performance, and value; and Implementing the project using the project scope.

Project managers may use many different tools during these major stages of project management. We will discuss how they can use a simple tool like SWOT analysis in some of these stages of project management.

\section{THE SWOT ANALYSIS}

SWOT Analysis is a strategic method for identifying whether to use a component in a project for example whether a new product development project is of any value to the organization. This analysis is a commonly used tool for identifying gaps and potential for improvement. SWOT stands for the internal Strengths and Weakness of a project and the external environmental Opportunities and Threats facing that project. When an effective project strategy derives from a sound fit between a project's internal resources (strengths and weaknesses) and their external situation (opportunities and threats), SWOT can be used in project management context. A good fit between the internal and external factors of a project will maximize the strength of a project while minimizing threats. It will also 
Volume XII, No. 1, pp. 237-245, 2011

minimize weakness of a project while maximizing success from opportunities. Figure 2 shows various factors to be considered to implement the objectives of SWOT analysis.

\begin{tabular}{|l||l|}
\hline \multicolumn{1}{|l|}{} & \\
Strengths: & Weaknesses: \\
All things that you do well & Your needs \\
All your assets & Lack of resources \\
Your core competencies & Things that you can do better \\
All factors that make your profits & All factors that make lose money? \\
All your expertise & Lack of experience \\
& \\
\hline \hline & \\
Opportunities: & Threats: \\
Customer needs that are not met & Competition \\
Trends that can benefit you & Trends that can hurt your business \\
Social and political opportunities & Negative social and political environment \\
New opportunities that can benefit you & New competitive forces \\
& \\
\hline
\end{tabular}

Figure 2. SWOT Factors

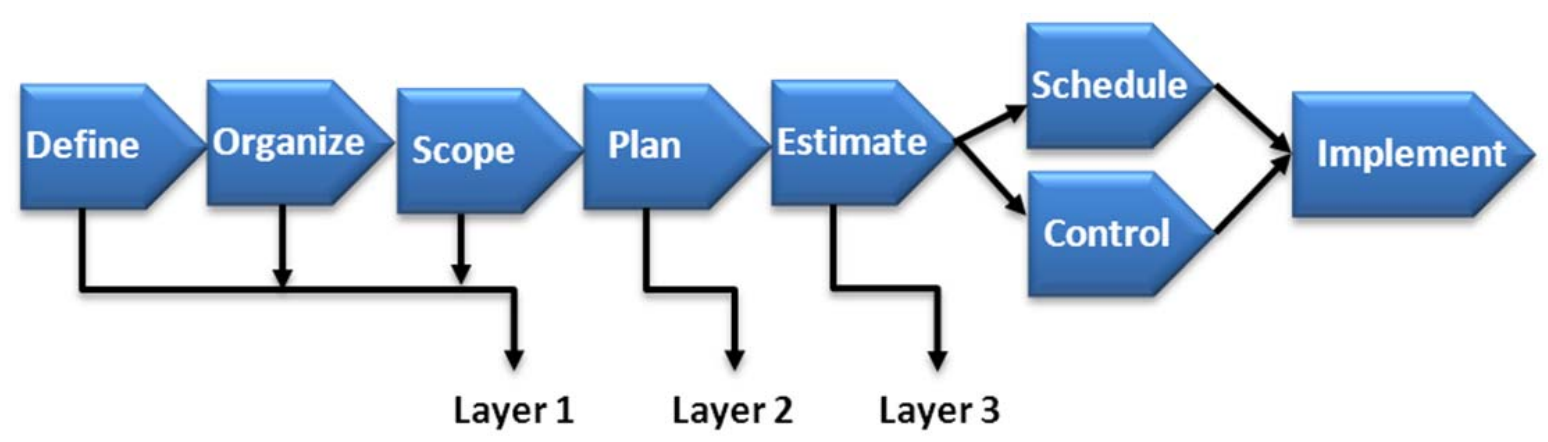

Figure 3. SWOT Analysis Layers and Stages of Project Management

In Figure 2, Strengths of a project are due to the appropriate resources and competencies used in projects. Strengths can be related to the project team, to the environment, to perceptions, and to elements that include the relevant skills, capabilities, and knowledge of participants. People strengths including friendly, cooperative and supportive stakeholders and appropriate levels of involvement through delegation and trust can be thought as strengths of a project. Weaknesses are limitations or deficiencies in one or more resources of a project. Weakness may include obstacles that prevent progress of a project, factors that need strengthening, and the weak links in projects. Project problems such as poor communication, inadequate leadership, lack of motivation, too little delegation and no trust can be major weaknesses in a project. Opportunities are situations in a project environment that may include new 
Volume XII, No. 1, pp. 237-245, 2011

technologies, new processes, and new regulations. Opportunities are usually available only for a short period and projects need to take advantage in that finite period. Threats are situations that may impede the progression and successful completion of a project including technology changes, revised regulations, and slow market growth. Same factors may emerge as both a threat and an opportunity, for example, new technology can be an enabler if used effectively and an inhibitor if not.

After identifying the SWOT factors, the next step is to devise new strategies. These new strategies may be devised using the proposed taxonomy of SWOT analysis at multiple levels. In the following sections, using the taxonomy of different levels of SWOT analysis, we show how to further the SWOT analysis. Organizations identify SWOT factors using Figure 2. So do project managers to identify SWOT factors in projects. However, SWOT analysis does not have to end at this point. It can be extended to multiple layers that may be used in different stages of project management as shown in Figure 3. We propose three layers of SWOT analysis that may be used at different times for different stages of project management. Layer 1 can be used during the definition, organization, and scope identification stages of project management. Layer 2 can be used during the planning of a project and Layer 3 can be used during the estimation of project. Let us discuss these layers in detail in the following sections of this paper.

\section{Layer 1 SWOT analysis}

New strategies may be short-term and long-term depending on their strengths and weaknesses of the project as well as the opportunities and threats of the environment as shown in Figure 4. The assumption here is that opportunities that are present before the project are of short-term only. There might be possible long-term opportunities but shortterm opportunities are the only ones that may be counted when devising strategies. The right upper quadrant in Figure 4 suggests strategies that take advantage of both the project's strengths and available external opportunities. The lower right quadrant shows strategies that face an unfavorable project environment when the project has major strengths. Project resource strengths may be used to build long-term opportunities in better markets or to reduce vulnerability to external threats. The lower left quadrant shows unfavorable position for the project as it faces major environment threats with internal weaknesses. The top left quadrant shows favorable market opportunity constrained by weak resources. These strategies may overcome weaknesses in projects to pursue opportunities. 
Volume XII, No. 1, pp. 237-245, 2011

Project Opportunities

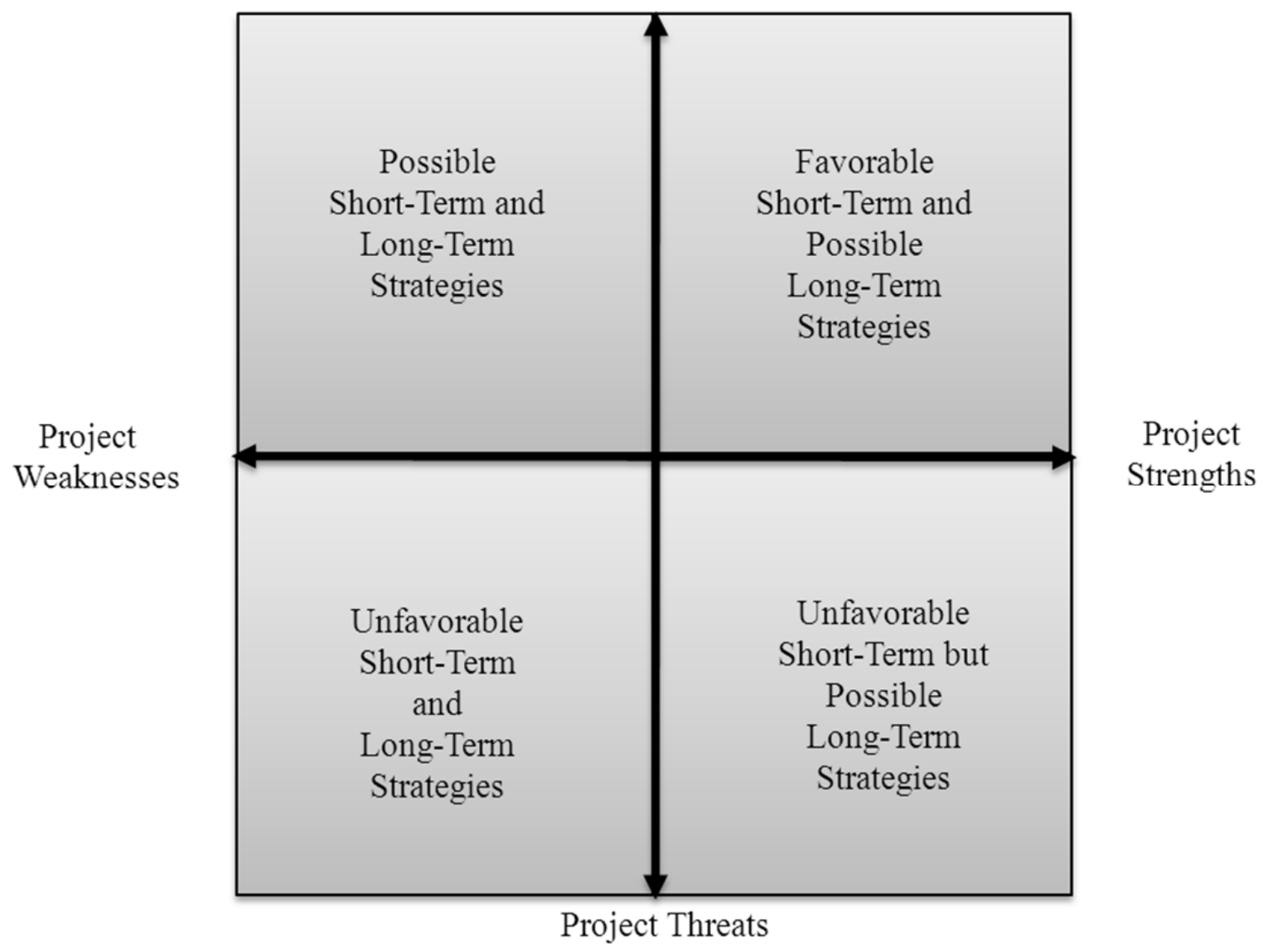

Figure 4. Layer 1 SWOT analysis

\section{Layer 2 SWOT Analysis}

The SWOT analysis shown in Figure 3 can be extended further to Layer 2, a second level analysis. Layer 2 is shown in Figure 5 and can be used for planning along with the original SWOT analysis shown in Figure 2. Projects can be classified in many different ways. Organizations perform routine task as well as innovative tasks, minor change (alpha) projects and major change (beta) projects [9]. Furthermore, there are in-house projects and outsourced projects as well as small projects and large projects. Projects in organizations are made up of many forms depending on the type of organization and the type of project. We classify projects as follows:

High Prioritized Projects (HPP),

Low Prioritized Projects (LPP),

Short-Term Projects (STP),

Strategy Creating Projects (SCP), and

Outsourced-Only Projects (OOP). 
Volume XII, No. 1, pp. 237-245, 2011

Organizations have HPP that provide value for the organization. HPP are projects that are handled by "in-house" staff provided the project has very high internal strengths that include expert staff within an organization and the core competencies of the organization. HPP can be outsourced as well or they can be pursued as a hybrid measure - partly outsourced and partly accomplished using "in-house" staff. LPP are not even attempted in an organization. STP are high rewarding projects that are pursued to take advantage of opportunities that are currently present in the horizon. SCP are projects that may be pursued when there is a need to create new projects that will be beneficial to the company at a later date when there are opportunities. These projects can be pursued to create strategic value to an organization when the right time emerges in the horizon. OOP are outsourced only projects. All projects have to be aligned to the strategy of an organization and during the planning stages of a project this taxonomy can be used to select projects based on the strategic importance of a portfolio of projects.

\section{Layer 3 SWOT Analysis}

Defining the goals and scope of a project, and developing plan for its implementation does not guarantee the successful implementation of the project. The implementation strategy is the most detailed component of the project management. It requires the estimation of budget, schedule, organizational constraints, and human resource issues among others. Careful considerations should be given to the estimation of the schedule and cost of the project; and the necessary resources to accomplish the required performance measures as well as to continuously monitoring 
Volume XII, No. 1, pp. 237-245, 2011
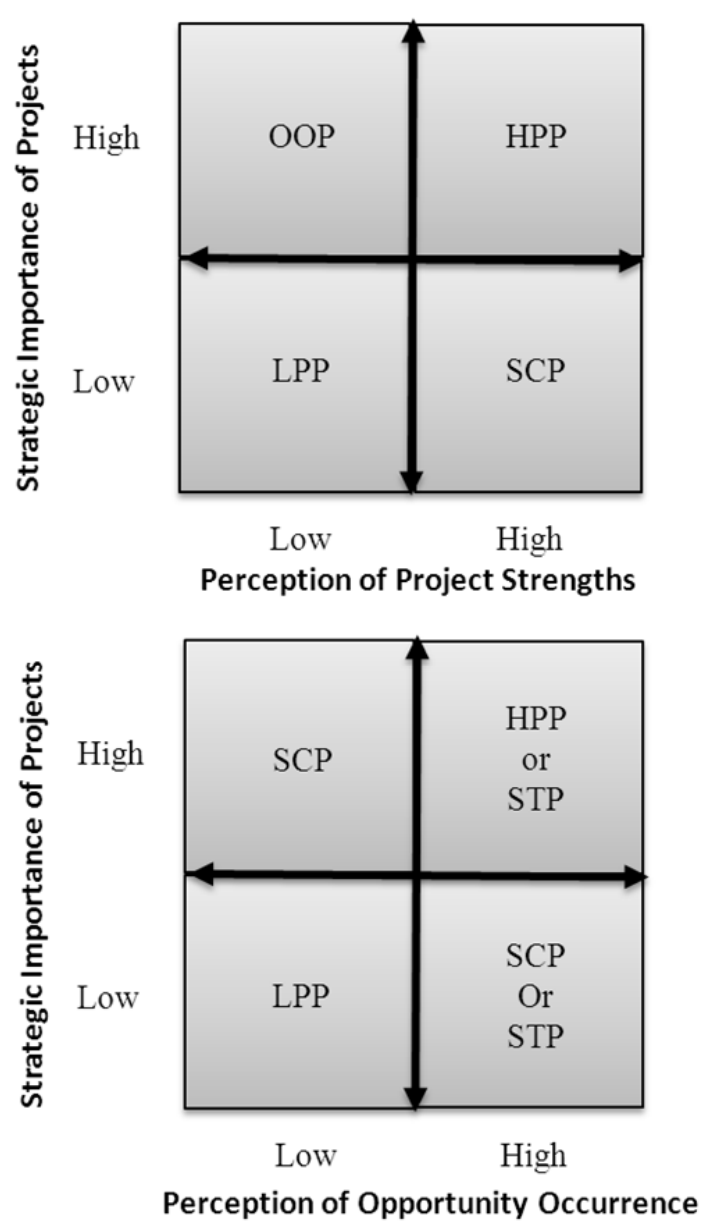
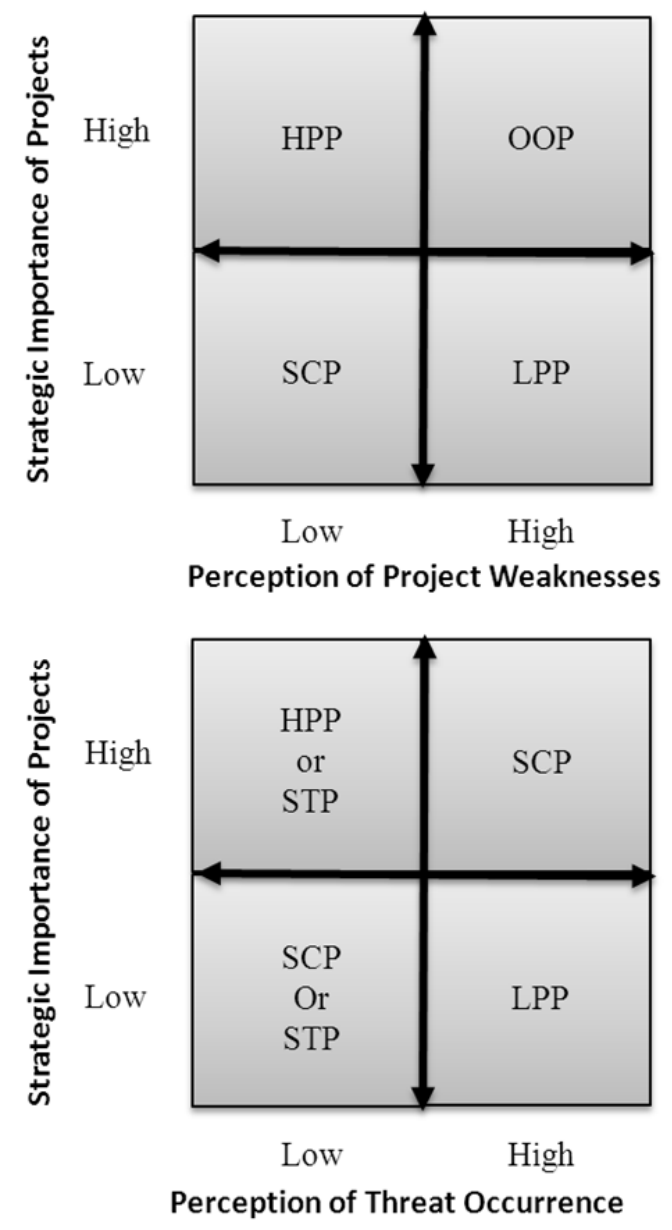

Figure 5. Layer 2 SWOT analysis

performance and implementation of the project during its life cycle. At this level, more effective management of internal resources (strengths), and slacks/shortcomings (weaknesses) would contribute to the success of the project. For example, skilled/experienced staff and workforce, high commitment to innovative technology by project managers, identifying higher value of projects, and stronger business development team are viewed as the strength of the project. On the other hand, effective management of user resistance to change, staff turnover and the quality staff being poached by other companies, changing technologies that require staff to be productive would help in successful implementation. Higher the effectiveness and efficiency of these internal resources and slacks would result to better estimation of project schedule and budget, and to better chance for successful implementation of the project. 
External environment and its uncertainty can affect the project performance through the potential opportunities and the risks. Project Management Institute [8] defines project risk as an uncertain event or conditions that, if it occurs, have a positive or a negative effect on a project objective [8]. Therefore, according to this definition, the risk includes both threats to the project's objective and opportunities to improve on those objectives [8]. This definition of risk encompassing both opportunities and threats, imply common processes for management of both opportunities and risks in an integrated approach. It is argued that opportunities and threats are not qualitatively different in nature as both involve uncertainty which has the potential to affect project objectives. The quantity and the quality of these opportunities and the threats depend on the effectiveness of management of these external uncertainties. According to PMI [8], the risk process includes six phases: (1) risk management planning, (2) risk identification, (3) qualitative risk analysis, (4) quantitative risk analysis, (5) risk response planning, and (6) risk monitoring and control. In each phase of this process, one needs to identify whether changes are required in order to explicitly include opportunities. In other words, management of opportunities in every project is an integral part of effective management of uncertainties and risks surrounding the project at this level. For example, Ecommerce using online technology has emerged as a new business model with many opportunities for growth for various businesses in the global market. Suppliers have been able to re-engineer business processes, create new and often automated business processes for higher speed and reliability of business, and create value through improved marketing and promotion, and better delivery of products and services as well as the production and operation of their processes. However, Most of these technologies applications may not have been tested for scalability, security, and availability [12].

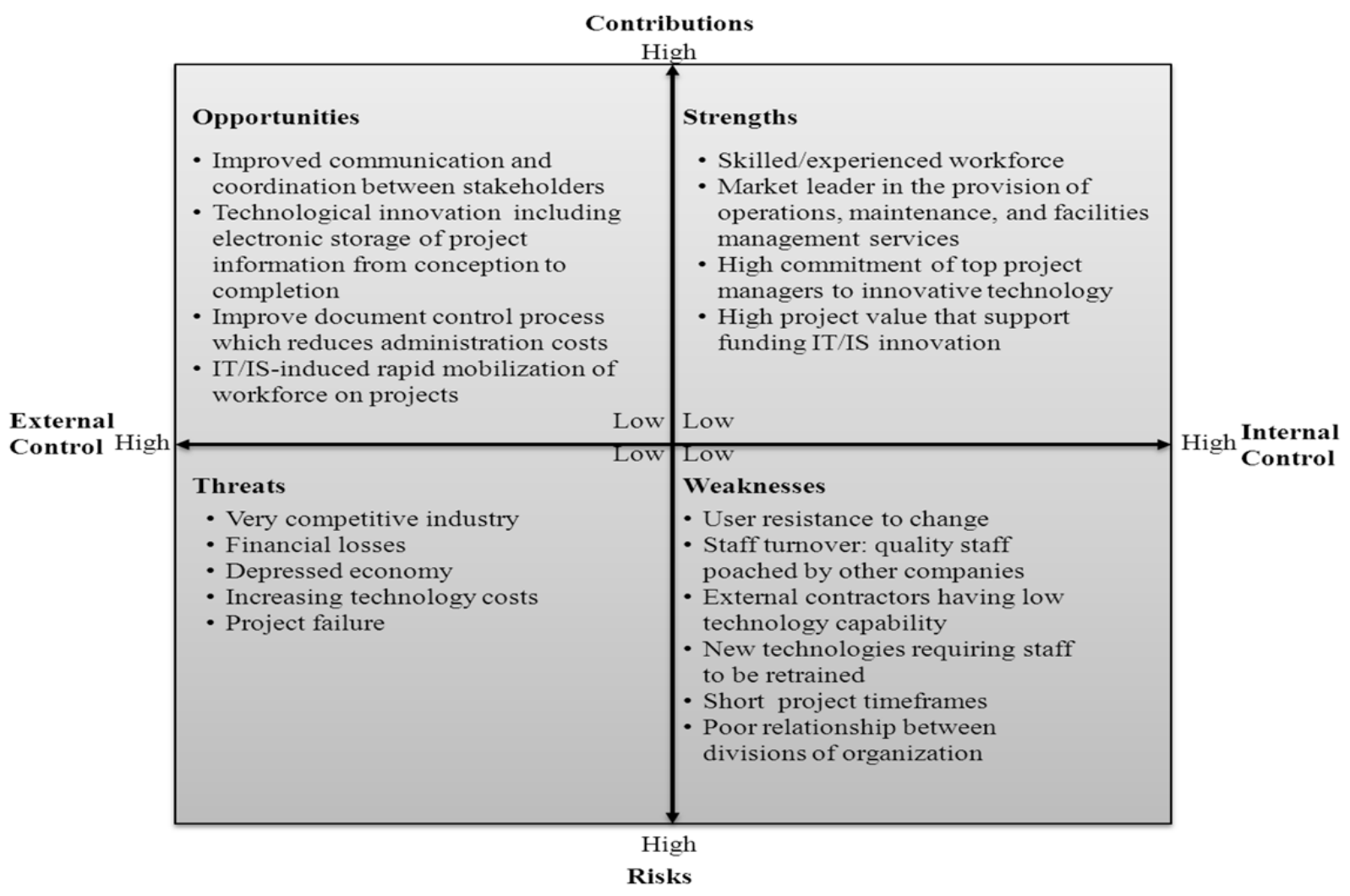

Figure 6. Layer 3 SWOT analysis

However, these new processes may have their own new risks. One may consider improved communication and 


\section{Issues in Information Systems}

$$
\text { Volume XII, No. 1, pp. 237-245, } 2011
$$

coordination between project teams, technological innovation, including electronic storage of project information from conception to completion, improve the document control process which reduces administration costs, technological-induced rapid mobilization of workforce on projects and paperless office reducing administrative overheads that positively contribute to the project success. Competitive industry, possible financial losses if project is mismanaged, depressed economy that causes a budget cut, increasing technology costs, and possible negative perception if project manager fails are examples of the risks and challenges caused by the external environment.

\section{CONCLUSION}

SWOT analysis is an easy and at the same times a powerful strategy for project managers to identify and understand various elements and dimensions of a project that, if managed properly, could contribute to its successful implementation. In particular, this proposed multi-layered SWOT analysis in this paper would help to magnify some of the hidden elements of internal resources for any project and external environment that are to be managed for successful project completion. Layer 1 can be used during the definition, organization, and scope identification stages of project management. Layer 2 can be used during the planning of a project and Layer 3 can be used during the estimation of project. The three layers may be used by project managers and stakeholders either to assess and mitigate project risks or even to terminate a project at some point. Particularly, we argue that at each stage, SWOT analysis could be more valuble when it is undertaken with more diligence and rigor in identifying various strengths, weaknesses, opportunities and the threats relevant to that specific stage of the project, and at the same time in an integrated approach, so that it can challenge the underlying assumptions and subsequent validations and investigation. We will expand this SWOT anaylis further in future studies to analyze various elements of a project such as scope, value, resources, cost, time, and performance with more specific cases from various industries. We continue to take an integrated approach in managing uncertainties and the opportunities/risks surrounding each dimension of the project management.

\section{REFERENCES}

1. Aritua, B., Smith, N.J., \& Bower, D. (2011). What risks are common to or amplified in programmes: Evidence from UK public sector infrastructure schemes, International Journal of Project Management, 29, 303-312.

2. Barber, R.B. (2005). Understanding internally generated risks in projects. International Journal of Project Management, 23, 584-590.

3. Baldry, D. (1998). The evaluation of risk management in public sector capital projects. International journal of project management, $16(1), 35-41$.

4. Chapman, C. (1997). Project risk analysis and management-PRAM the generic process. International Journal of Project Management, 15 (5), 273-281.

5. Chapman, C., Ward, S. (2004). Why risk efficiency is a key aspect of best practice projects. International Journal of Project Management, 22, 619-632.

6. Cooper, R.G., Edgett, S.J., \& Kleinschmidt, E.J. (1998). Best practices for managing R\&D portfolios. ResearchTechnology Management, 41(4), 20-33.

7. Jamieson, A., \& Morris, P.W.G. (2004). Moving from corporate strategy to project strategy. In P.W.G. Morris and J.K. Pinto (Eds.). The Wiley Guide to Managing Projects. Hoboken, NJ: John Wiley \& Sons.

8. PMI (2008). A guide to the project management body of knowledge. Newtown Square, PA: Project management Institute.

9. Shenhar, A. (2001). One Size Does Not Fit All Projects: Exploring Classical Contingency Domains. Management Science, 47 (3), 394-413.

10. Wikipedia (2011). Available at http://en.wikipedia.org/wiki/SWOT analysis and accessed on July 12, 2011.

11. Williams, T.M. (1994). Using a risk register to integrate risk management in project definition. International Journal of Project Management, 12(11), 17-22.

12. Vaidyanathan, G. (2007). E-Business risk management in firms. In E-Business Processes: Technologies and Solutions. Eds. Jayavel Sounderpandian and Tapen Sinha. Hershey, PA: IDEA Group Inc. 